\title{
Using MCDA to enable individual preference-based matchmaking in the sustainable mobility domain
}

\author{
Sven Kölpin ${ }^{1}$ Daniel Stamer ${ }^{1}$ Benjamin Wagner vom Berg ${ }^{1}$ \\ ${ }^{1}$ University of Oldenburg, Oldenburg, Germany \\ \{sven.koelpin,daniel.stamer,benjamin.wagnervomberg\}@uni-oldenburg.de
}

\begin{abstract}
This work provides a foundation to make heterogeneous alternatives for mobility (transportation modes) comparable in the context of sustainability and providing possibilities to also compare them in other contexts such as costs or flexibility. The key to a successful comparison of such transportation modes is stated as the selection of semantically suitable key performance indicators (KPI) and a reasonable decision analysis method, which will be covered throughout this work. A set of KPIs is selected by considering various existing indicators, like indicators for measuring resource consumption or air pollution. This work provides a method for comparing the relative sustainability or any other desired dimension, given the requirement that a suitable set of KPIs is selected, of multiple modes of personal transportation by using key performance indicators and the multi-criteria decision analysis method PROMETHEE II. In addition to the introduced objective decision support, the authors also provide a way to enable subjective decision support by taking the preference-based model of an individual decision-maker into account. A method to enable individual preference based matchmaking is introduced to provide the mathematical foundation for mapping each individual to their subjectively optimal transportation mode. Some possible practical use cases which are able to create real world added value by automated appliance of the introduced models are given by the authors as well..
\end{abstract}

Keywords: Multi-criteria decision analysis, PROMETHEE II, decision support, matchmaking, sustainable mobility, KPI for sustainability

\section{Introduction}

Today companies, governments and the public are recognizing that resources are limited (e.g. oil) and different other problems are occurring in the economic, environmental and social dimension that are resulting from our economic acting and our consumption behaviour [3]. Because of this, sustainability is growing into a major topic for companies as well as for customers.

Especially the energy sector is seeking for alternatives, because it has to deal with huge environmental impacts (hazardous nuclear power, carbon dioxide - $\mathrm{CO}^{2}$ - emissions by fossil burning plants) and upcoming shortages (peak oil). An actual report of the Intergovernmental Panel on Climate Change (IPCC) proclaims that it is possible to produce $77 \%$ of the worldwide needed energy with regenerative power plants like wind energy, solar and others [8].

Mobility has a huge impact in the energy and sustainability context. So $26 \%$ of worldwide $\mathrm{CO}^{2}$ emissions by combustion of fuel are coming from transport and 35\% of total energy consumption in Europe is coming from transport with $71 \%$ by road traffic [9]. Switching to electric vehicles (EV) seems to have a huge potential for a fundamental change to a more sustainable transportation with less $\mathrm{CO}^{2}$ emissions and less energy consumption. But also EVs have environmental impacts and furthermore technical shortages. So a 1:1 substitution of conventional cars $(\mathrm{CV})$ by EVs is both not sufficient according sustainability and on basis of today's technology not possible [26].

All of these considerations suggest that there is no such thing as a simple solution to the problem. Furthermore the insufficient substitution of CVs by EVs (without altering the conventional energy mixes) needs to be evaluated so we can provide a better understanding of why this substitution is failing.

In order to provide a base for a possible solution to this problem, we will need to establish a method to compare the competing modes of personal transportation first. This approach follows the well-established management by objectives in its central idea: "What gets measured gets managed" [7].

This work establishes a method for the measurement of mobility in the sense of providing a method for comparing competing modes of transportation among each other. The aim is to find a set of tools, which can be applied on a set of different alternatives for personal mobility. Note that these different alternatives only differ in a limited amount of perspectives; they still transport their common customer from the same common origin to the same common destination in a fixed window of time. The appliance of the mentioned tools will then result in a relative comparison of the alternatives, rating them according to their behaviour in the context of sustainability.

To achieve this we will need to define the terms of 'mobility', 'sustainability' and its composition 'sustainable mobility' at first. This first clarification of relevant terminologies puts emphasis on the well-known term of 
sustainability and selects a clear definition of what we are referencing in the further sections of this work.

In order to measure alternatives for mobility we must then find a suitable set of key performance indicators (KPI). This work will only focus on assembling sets or systems of KPIs for certain types of vehicles.

After providing the calculatory foundation for measurement, a method for evaluating the different modes of transportation needs to be found. To find a suitable method we need to define the type or class of method at first. Afterwards we can pick the most suitable method from that definition and set it up for use. Finally this work provides considerations of use cases or appliances in which the assembled set of tools can be used practically.

Furthermore, an advanced variation of the toolset is introduced which allows to enhance the objective decision support system to enable subjective matchmaking. This enhancement takes the mere fact into account, that the travelling individuals are heterogeneous according to their preferences in mobility.

This final section gives numerous insights on how to generate added value by implementing the method.

\section{Sustainable mobility}

In this section we will combine the terms of sustainability and mobility. To achieve this we need to cover the definition of these terms for themselves at first. Additionally we want to weight the different dimensions of sustainability for the topic of mobility. Throughout the clarification of these terms we will gather some theoretical foundations for the evaluation of sustainability in further sections of this work.

\subsection{Mobility}

Mobility is what is commonly referred to as the possibility of movement. The term includes the movement of persons and items, in the sense of moving them in a strictly physical manner. However, persons may also move in a spiritual or social way [28]. The term of mobility is often equated with the term of traffic. To clarify this one must understand that traffic is the actual movement of persons, goods or messages in a fixed system [1]. Therefore traffic is the result of applied [28]. This concludes that there must be different sets of KPIs for the measurement of traffic and mobility. For example: to measure the amount of mobility in one region one must determine the rate of mobility. This rate consists of the average number of ways which are travelled by one individual in a given amount of time [18]. On the other hand the amount of traffic describes the average number of ways travelled by every individual in a given amount of time.

Traffic is therefore one possible option for realizing mobility. This concludes that one individual must have several other ways to realize mobility, without causing traffic. On the other hand it is possible to create large amounts of traffic without having a large amount of pos- sibilities for mobility. The aims of this work is to provide utilities for measurement of mobility so these utilities can be used in future works to reduce the amount of traffic while increasing the possibilities for mobility.

\subsection{Sustainability}

The usually quoted definition for sustainability is the following one of the Brundlandt commission from the year 1987: "Permanent development is development, which satisfies the needs of the present, without risking that future generations do not satisfy their own needs [13]'”. This definition makes clear, that sustainability means more than a long-term protection of profits and enter-prise maintenance. Sustainable management means to act resource-protective and to take further goals from the social and also the cultural range into focus. To classify the dimensions of sustainability the three pillars of sustainability according the Lower German House of parliament can be differentiated: ecological dimension, social dimension, financial (economical) dimension.

\subsection{Sustainable Mobility}

The composition of the latterly introduced terms into the term of 'sustainable mobility' can best be described by looking at two existing definitions. The first one by Gottschalk [12] defines sustainable mobility as the following:

"Sustainable Mobility is the ability to meet society's need to move freely, gain access, communicate, trade and establish relationships without sacrificing other essential human or ecological values, today or in the future."

On the other hand [5] describes the term a bit differently. Dangschat's definition states that the term 'sustainable mobility' is a collective term for all changes in everyday life, technological development economical system, which allow us to increase the mobility of persons to satisfy the needs of everyday life while decreasing the amount of traffic.

Just like the latterly introduced definition of the 'sustainability' both definitions of the term 'sustainable mobility' share a common idea. All of the definitions reference the need to not exploit the social, economic and ecological resources of future generations by actions taken today. In addition to that, both definitions point out the importance of mobility for the present society. This concludes that there must be a trade-off between the sustainable development of mobility and the requirements on mobility issued by society. This trade-off suggests two options for a possible course of action. A strategy of sufficiency (the abandonment of mobility) is one way to encounter the problem and a strategy of efficiency is the other. The latter option requires sustainable innovations and should be pursued throughout this work. According to Schwarz [20] it is important to find a well balance compromise between the pillars of sustainability. Therefore it 
is important to weigh the use of the three dimensions in the further work.

To enable sustainable mobility one must first put heavy emphasis on the ecological dimension of sustainability. This dimension is preferably chosen because its positive effects may also cause positive effects within the social and economic dimension of sustainability. This thesis is underpinned by the Umweltbundesamt and Dalkmann [5].

\section{Key performance indicators for mobility}

Key performance indicators (KPI) are mostly used in managerial functions like controlling. They represent numbers that contain special information for businesses, especially for the management [27]. Indicators are used to inform about the current state of a company. One of the most important characteristics of a KPI is that it makes information quantifiable, which enables the measurability and comparability of situations [17]. KPIs are therefore especially suited to simplify complex issues and to make them comparable.

In this work, general key performance indicators are used to make the sustainability of various means of transportation comparable. The aim is to represent the three pillars of sustainability by various indicators. Because of the reasons pointed out in section 2, the focus of the indicators will be set on the ecological pillar.

\subsection{Considered means of transportation}

The means of transportation investigated in this work are shown in table 1 . The table is based on a report by [16] which was commissioned by the Umweltbundesamt. The focus of this work is on means of transportation that are used in urban areas. The data on the consumption of the car models are average values for urban areas. They also consider the cold-start units. An additional average consumption of $25 \%$ is considered on the consumption of natural gas buses. The emission calculation of a tram and $\mathrm{PEV}$ is based on the typical electricity mix in Germany.

The final primary energy consumption of the considered transport in urban areas depends on many different parameters. These include:

- Vehicle-specific parameters (curb weight, air resistance)

- Motor Technical parameters (injection method)

- Equipment (heating, air conditioning)

- Vehicular parameters (wind, flowing traffic)

- Topographic Parameters (flat or hilly terrain)

These parameters are observed only partially by [16] This is due to the fact that the factors differ from city to city and sometimes even within a city. Therefore, the results presented in table 1 are only based on expert interviews and literature reviews, but they reflect the reality.

\begin{tabular}{|c|c|c|c|c|}
\hline Vehicle & $\begin{array}{l}\text { En- } \\
\text { ergy } \\
\text { type }\end{array}$ & $\begin{array}{l}\text { Final } \\
\text { energy } \\
\text { con- } \\
\text { sump- } \\
\text { tion }\end{array}$ & $\begin{array}{l}\text { Number } \\
\text { of seats }\end{array}$ & $\begin{array}{l}\text { Primary } \\
\text { energy } \\
\text { (kj/seat-km) }\end{array}$ \\
\hline Car & Otto & $\begin{array}{l}6-15 \\
\mathrm{l} / 100 \\
\mathrm{~km}\end{array}$ & 5 & $460-1140$ \\
\hline Car & $\begin{array}{l}\text { Die- } \\
\text { sel }\end{array}$ & $\begin{array}{l}3,5-11 \\
\mathrm{l} / 100 \\
\mathrm{~km}\end{array}$ & 5 & $280-890$ \\
\hline Bus & $\begin{array}{l}\text { Die- } \\
\text { sel }\end{array}$ & $\begin{array}{l}40 \\
\mathrm{l} / 100 \\
\mathrm{~km}\end{array}$ & 66 & 244 \\
\hline $\begin{array}{l}\text { Articu- } \\
\text { lated } \\
\text { Bus }\end{array}$ & $\begin{array}{l}\text { Die- } \\
\text { sel }\end{array}$ & $\begin{array}{l}55 \\
\mathrm{l} / 100 \\
\mathrm{~km}\end{array}$ & 102 & 217 \\
\hline Bus & $\begin{array}{l}\text { Natu } \\
\text { ral } \\
\text { gas }\end{array}$ & $\begin{array}{l}49,7 \\
\mathrm{~m}^{3} / 100 \\
\mathrm{~km}\end{array}$ & 66 & 327 \\
\hline $\begin{array}{l}\text { Articu- } \\
\text { lated } \\
\text { Bus }\end{array}$ & $\begin{array}{l}\text { Natu } \\
\text { ral } \\
\text { Gas }\end{array}$ & $\begin{array}{l}68,3 \\
\mathrm{~m}^{3} / 100 \\
\mathrm{~km}\end{array}$ & 102 & 291 \\
\hline Tram & $\begin{array}{l}\text { Elec- } \\
\text { tric- } \\
\text { ity } \\
\end{array}$ & $\begin{array}{l}28 \\
\text { Wh/sea } \\
\text { t-km }\end{array}$ & n.a. & 309 \\
\hline PEV & $\begin{array}{l}\text { Elec- } \\
\text { tric- } \\
\text { ity }\end{array}$ & $\begin{array}{l}40 \\
\text { Wh/sea } \\
\text { t-km }\end{array}$ & $2-4$ & 340 \\
\hline
\end{tabular}

Table 1: Considered means of transportation [16], [10]

\subsection{Making key performance indicators comparable}

The problem of using key performance indicators for the evaluation of the sustainability of different means of transportation is the huge difference between the vehicle types. For example, the carbon emissions of a bus will always be much higher than the emissions of a car because the bus has a higher energy consumption.

This is why the actual utilization rate of a vehicle has to be considered when calculating the concrete values of an indicator. The utilization rate refers to the ratio of available space numbers and actually occupied seats in a vehicle.

By using the actual utilization rate to calculate the indicator values, the differences between the various means of transportations can be compensated and a comparable data basis for the evaluation of the relative sustainability of a vehicle is created.

\subsection{Considered key performance indicators}

This chapter describes the indicators used for the comparison of different vehicle types. The indicators represent the three pillars of sustainability for mobility.

\subsubsection{Indicator for consumption of resources}

This indicator can be considered as an indicator for the ecologic and economic pillar of sustainability. It is an indicator for the ecologic pillar because the exploitation of natural resources, especially of fossil fuels, does have a huge impact on the environment. Because resource policy does have a massive impact on the national economic, this indicator is also for the economic pillar. The indicator is the basis for the air pollutants which are described next. 


\subsubsection{Indicators for air pollutants}

This section covers the most important indicators for the ecologic pillar of sustainability. The indicators represent the most important types of emissions. The selection of the indicators of this section is based on the indicators used in the COPERT-Software which is developed by the European Environment Agency [2].

Greenhouse effect - The most considered challenge in the context of environmental sustainability and traffic is the reduction of the greenhouse effect to prevent the climate change. The influence of a vehicle to the greenhouse effect is measured in carbon dioxide equivalents. In addition to the carbon dioxide emissions, the gases methane (CH4) and nitrous oxide (N20) contribute to the greenhouse effect. The effects of carbon dioxide emissions are not immediately perceptible to humans. This is why this indicator should be considered in its global impact.

Particulates (PM10) - Particulates are dust particles which have a diameter of 10 microns or less [15]. Particulates are especially harmful to humans because they are inhaled unnoticed and may enter the bloodstream. This can result in asthmatics, heart attacks and strokes [22].

Particulate emissions are not only caused by the burning of fossil fuels, but also by dust swirls and abrasion, which for example is caused by braking. Because most of the particulates emissions are caused by traffic, the exposure in urban areas is much higher than in rural areas. Especially heavy vehicles such as buses contribute to the high amount of emissions. For this reason, in 2007, environmental zones have been introduced in many cities in Germany. According to the Umweltbundesamt this caused a reduction in PM-10-emissions by approximately $10 \%$.

Nitrogen oxides - Nitrogen oxides are created during the combustion at high temperatures. About $96 \%$ of nitrogen oxides emitted can thereby be associated with the transport section [25]. The combustion of diesel fuel creates much more NOx emissions than the combustion of gasoline. The effects of an increase of nitrogen oxides on the environment and the people are different. Especially eutrophication is a major problem. An increase of the nitrogen compounds in the soil can cause chronic damage to the flora and fauna [23]. But also the formation of acid rain and smog, NOx is one of the precursors of ozone, are known issues.

Summer smog - Smog or ozone is not directly caused by vehicles. Ozone gases are formed by sunlight from nitrogen oxides and volatile organic compounds, which in turn are caused by road traffic. Since solar radiation is needed for the formation of ozone, the ozone level usually in- creases in the summer. This means that the formation of ozone gases is highly dependent on weather and on time.

Ozone gases have a direct impact on human health. The gas irritates the mucous membranes and has negative effects on respiration. In addition, plants can be permanently damaged by ozone gases.

\subsubsection{Indicator for noise pollution}

This indicator can be considered as an indicator for the ecologic and social pillar of sustainability. It is an indicator for the ecologic pillar, because noise is influencing the environment. Also noise pollution can be seen as an indicator for the social pillar, because it influences the life quality of a city which has a huge impact on the demographic composition.

The traffic noise is a permanent disturbance in cities and can have a significant impact on human health. According to the Umweltbundesamt, traffic noise can lead to an increased release of stress hormones and increases the risk for diseases.

Motorised road transport is a major source of noise pollution in urban areas. According to a calculation of the Umweltbundesamt, half of the population is exposed to noise whose level is above $55 \mathrm{~dB}(\mathrm{~A})$ per day. About one seventh is even exposed to a level of about $66 \mathrm{~dB}(\mathrm{~A})$.

The calculation of the noise pollution indicator values are based on the computational model CITAIR which was introduced by the Umweltbundesamt. This model allows the calculation of the average sound levels for any traffic situations.

\subsubsection{Indicator for Human Toxicity}

This indicator measures the impact of road transport on human health. It is thus a measure of the social dimension of sustainability.

This indicator is fully dependent on the already described emissions caused by road transport. Above all, the air pollutants are considered to have a direct impact on the local environment, and thus to humans.

\subsubsection{Indicator for land consumption}

This figure is relevant for both the economic and the social dimension of sustainability. Area is a valuable and very limited resource in a city. The traffic, most of all traffic caused by cars, plays a major role in the space consumption. Increased traffic leads to a higher consumption of space and thus to an impaired quality of life of the urban population.

The maintenance costs for the traffic infrastructure have a high relevance for the economic point of view. Each mode of transport causes an erosion of the transport infrastructure. This condition requires repairs that are often financed with money from public funds which can possibly lead to increased debts. 


\section{Method for the comparison of the relative sustain- ability of vehicles}

For a correct evaluation of the relative sustainability of a vehicle, a calculation model that enables the comparison of various alternatives on the basis of heterogeneous criteria and indicators needs to be used. Depending on various parameters, such as vehicle utilization, the traffic situation and even the weather, a ranking for the sustainability of various modes of transportations needs to be created at a specify point of time. Multi-criteria decision support systems (MCDA) provide this exact functionality.

In this work, we used the outranking method PROMETHEE II as a decision support system to create a relative ranking. The PROMETHEE method is one of the outranking methods, which allow a complete ranking of various alternatives based on a variety of criteria [21]. It was developed in 1985 by Brans \& Vicke. The advantage of PROMETHEE method is that it takes all available criteria into consideration. All alternatives are compared pairwise and advantages and disadvantages can be considered separately from each other. Furthermore, preference functions can be used during the comparison of alternatives, which allows to model indifferences between the criteria.

In contrast to PROMETHEE I, PROMETHEE II creates a total ranking of alternatives and does not support incomparabilities. In our use case, we want a total ranking of all considered vehicles at a specific point of time. Also incomparabilities, which do not allow a total ranking and can only be modelled with PROMETHEE I [11], are not considered in our use case. This is why the PROMETHEE II method fits best to our multi-criteria decision problem.

As said before, PROMETHEE II allows a total ranking of various alternatives on the basis of various criteria. In the use case of this work, the alternatives are represented by different types of vehicles and the criteria are the key performance indicators explained in section 3.3. This allows us to create a total ranking of the sustainability of all available vehicles at a specific point of time. The ranking heavily depends on the actual utilization of a transport. The table 2 shows an example of an achievement matrix that needs to be created as a first step. In this simplified example, an actual utilization of five persons per vehicle is assumed.

\begin{tabular}{|l|l|l|l|l|}
\hline $\begin{array}{l}\text { Alternatives / } \\
\text { Criteria }\end{array}$ & $\begin{array}{l}\text { Car (Otto) } \\
\mathbf{5} \text { Seats }\end{array}$ & $\begin{array}{l}\text { Car } \\
\text { (Diesel) } \\
\mathbf{5} \text { seats }\end{array}$ & $\cdots$ & $\begin{array}{l}\text { Bus } \\
\text { (Diesel) } \\
\mathbf{7 5} \text { seats }\end{array}$ \\
\hline $\begin{array}{l}\text { Consumption of } \\
\text { resources }\end{array}$ & $\begin{array}{l}700 \mathrm{kj} \mathrm{/} \\
\text { person-km }\end{array}$ & $\begin{array}{l}620 \mathrm{~kJ} \mathrm{/} \\
\text { person- } \\
\mathrm{km}\end{array}$ & $\cdots$ & $\begin{array}{l}3150 \mathrm{~kJ} / \\
\text { person- } \\
\mathrm{km}\end{array}$ \\
\hline$\cdots$ & $\ldots$ & $\ldots$ & $\cdots$ & $\cdots$ \\
\hline $\begin{array}{l}\text { Greenhouse effect } \\
\text { (CO }{ }^{2} \text {-equivalents) }\end{array}$ & $\begin{array}{l}55 \mathrm{~g} / \text { per- } \\
\text { son-km }\end{array}$ & $\begin{array}{l}\text { 48g / } \\
\text { person- } \\
\mathrm{km}\end{array}$ & $\cdots$ & $\begin{array}{l}270 \mathrm{~g} / \\
\text { person- } \\
\mathrm{km}\end{array}$ \\
\hline
\end{tabular}

Table 2: Example of an achievement matrix for the use case
Table 3 shows the final flow matrix for the example above. It shows that in this trivial example with a utilization of 5 persons, a bus would be the least sustainable transport mode one could use at this point of time, whereas the car with a diesel combustion engine would be the most sustainable transportation mode. Note that $\mathrm{F}^{+}$describes the aggregated advantages and $\mathrm{F}^{-}$the aggregated disadvantages of an alternative.

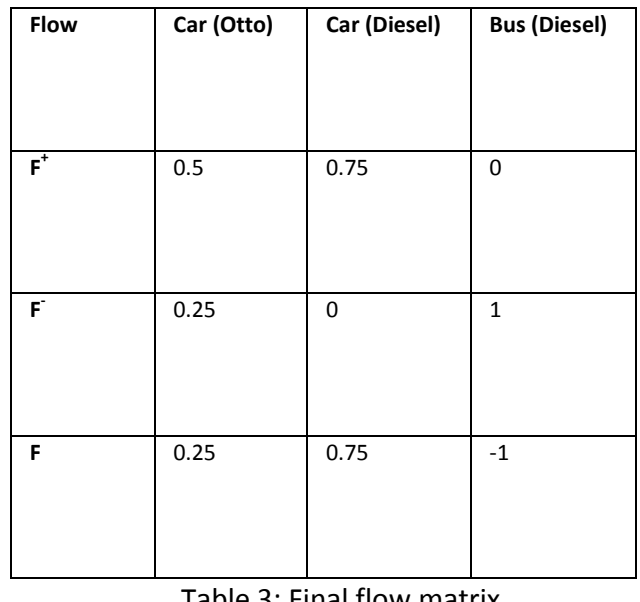

\section{Individual preference-based matchmaking}

The previous defined method describes how to support an objective decision using a suitable set of KPIs and the multi-criteria decision analysis method PROMETHEE II. This model can easily be extended by other key performance indicator systems. The goal is to not only use the introduced method to rank the sustainability of various transportation modes, but to find the best fitting transportation for an individuals' needs at a specific point of time. For example, the shown key performance indicator system which represents the sustainability can be extended by various other systems, such as KPIs that allow the evaluation of the costs or flexibility of a transportation mode.

Each evaluation of a KPI system (such as costs, flexibility) done with PROMETHEE II can then be used to provide a multi-dimensional description of a transportation mode. This concludes that a transportation mode can be described by a vector in which every index corresponds to one relative evaluation of a KPI system by PROMETHEE II. The structure of this vector mode is shown in (1) alongside with reasonable example data. Vector describes an evaluated transportation mode, is a dimension in a result of a relative comparison among all evaluated modes of transportation done with PROMETHEE II. Note that the result values of evaluation must range from -1 to 1 . 


$$
\begin{gathered}
T_{1}\left(\begin{array}{l}
D_{p \text { Sustainability }} \\
D_{p \text { Costs }} \\
D_{p \text { Flexibility }}
\end{array}\right)=T_{1}\left(\begin{array}{r}
0,25 \\
0,75 \\
0,95
\end{array}\right), D_{p i} \in[-1,1] \\
T_{1}\left(\begin{array}{l}
D_{p \text { Sustainability }} \\
D_{p \text { Costs }} \\
D_{p \text { Flexibility }}
\end{array}\right)=T_{1}\left(\begin{array}{r}
0,5 \\
0,75 \\
-1
\end{array}\right) D_{p i} \in[-1,1]
\end{gathered}
$$

To enable an individual preference-based matchmaking to support subjective decision we will need to model the preferences of the individuals at first.

In order to achieve a comparable model the individuals' preferences have to be modelled in a similar way. Additionally there may be more than one instance of preferences for each individual. The structure of each preference is portrayed in (2). The additional constraint is used to enforce weighting of at least one dimension in the preference vector.

$$
P_{i}\left(\begin{array}{l}
D_{c \text { Sustainability }} \\
D_{c \text { Costs }} \\
D_{c \text { Flexibility }}
\end{array}\right), D_{c i} \in[-1,1], \sum D_{c i}=0
$$

The main difference between and is that preferences in are chosen by the individual whereas transportation modes in are evaluated with PROMETHEE II. Additionally we want the individual to be described by a set of preferences, hence the index on .

To enable the preference-based matchmaking we must at first unify the preferences to describe the total target of the match. This is done by a simple addition of all preference vectors. Note that in contrast to and the vector does not have any restrictions for the codomain of its values.

Afterwards the vector is multiplied with the evaluations of each transportation mode. The resulting vectors of the multiplication depict the potential subjective value that is created by choosing the corresponding transportation mode. This concludes that the biggest sum of identifies the optimal transportation mode for the individual at hand. The relevant mathematical definitions for this are shown

in

$$
\begin{aligned}
& P_{\text {target }}=\sum p i \\
& T_{P i}=P_{\text {target }} * T_{i} \\
& T_{\text {best }}=\max \left(T P_{i}\right)
\end{aligned}
$$

\section{Practical use case}

The assembled set of suitable KPIs in combination with the PROMETHEE multi-criteria decision analysis method can be used to compare different possibilities for mobility according to the context of various dimensions such as sustainability, costs and flexibility.
Such a comparison is very useful for a user, who has a current demand for mobility. It allows a user to compare a set of possible alternatives that would satisfy his current need for mobility. Applying the developed method would result in a relative assessment of the different alternatives, so the user can clearly determine which of the alternatives would be the most suitable one.

Furthermore, an automated implementation of the method can be very useful within a multimodal route planning software. Such software would typically respond to a specific user request in which the user issues his demand for mobility by specifying several parameters like origin and destination of travel and a desired time frame in which he wishes to travel. The route planning software would then respond with a set of possible alternatives that have the potential of satisfying his demands.

Software like such a route planner could integrate an automated version of the developed method into its result set. It would not only respond with a set of possible alternatives for mobility, but also with additional information on the ecological impacts and consequences that are tied to the actual use of an alternative. This integrated approach would not only eliminate the need of manual calculation by the user but also enhance the user's perception of the implications that go hand in hand with his daily traveling.

The development of a software prototype which focuses on the implementation of the above mentioned possible use case is currently in progress at the University of Oldenburg. The project's aim is to provide a route planning software that stresses the sustainable aspects of the returned results. In addition to that the project tries to implement incentive systems with the goal to influence the users of the software in a way that would push a user towards a more sustainable way of travelling. A similar approach has already been undertaken by a former project which was also located progress at the University of Oldenburg [14].

\section{Conclusion}

This work introduces a method which enables the comparison of a mode of transportation on the basis of key performance indicators and multi-criteria decision analysis. The key performance indicator systems represent various attributes of a mode of transportation and enable to make these attributes measureable. The multi-criteria decision analysis method PROMETHEE II makes use of the KPIs and helps to find the situation-dependent relatively best mode of transportation. Building on this method, a user preference-based model, which uses the results of various multi-criteria decision analyses, is introduced. This model enables to always find the best suiting mode of transportation for a specific user at a particular point of time. As explained, the introduced method is already used and implemented in practice. At the moment, only key performance indicators that represent the sustainability of a mode of transportation are used. In fu- 
ture work, the key performance indicator systems that allow the real time evaluation of other attributes of vehicles such as the costs and the flexibility have to be implemented.

Another further idea is to extend the dynamic aspects of the introduced method. At the moment, only the actual utilization of a vehicle is influencing the value of a key performance indicator. In reality, there are a lot of more parameters, such as the weather, the time or the current traffic situation, that have an impact on the KPI-values. In future these aspects should also be covered by the introduced method.

\section{References}

[1] H. Ammoser and M. Hoppe, Glossar Verkehrswesen und Verkehrswissenschaften, TU-Dresden, Dresden, 2006.

[2] H.-J. Becker and M. Schreiber, Berechnung von Verkehrs-bedingten Schadstoffemissionen, Technische Universität Berlin, Berlin, 2006.

[3] F. Belz and K. Paettie, Sustainability Marketing - a global perspective, Chichsester, West Sussex: Wiley \& Sons, 2009.

[4] M. Caspers-Merk and E. Fritz, Abschlussbericht: die Enquete-Kommission "Schurtz des Menschen und der Umwelt - Ziele und Rahmenbedingungen einer nachhaltigen zukunftsverträglichen Entwicklung,“ Deutscher Bundestag, Berlin, 1998.

[5] H. Dalkmann, C. Schäfer-Sparenberg and R. Herbertz, Eventkultur und nachhaltige Mobilität Widerspruch oder Potential?," Wuppertal Papers Institut, Wuppertal, 2004.

[6] J. Dangschat and A. Segert, Nachhaltige Alltagsmobilität - soziale Ungleichheiten und $\mathrm{Mi}$ lieus, " Österreichische Zeitschrift für Soziologie, pp. 55-73, 01022011.

[7] P. Drucker, The practice of management, New York: Harper Business, 2006.

[8] O. Edenhofer, R. Pichs-Madruga, Y. Sokona, K. Seyboth, P. Matschoss, S. Kadner, T. Zwickel , P. Eickermeier, G. Hansen, S. Schlömer and C. v. Stechow, Summary for Policy Makers, in IPCC Special Report on Renewable Energy Sources and Climate Change Mitigation, Cambridge, 2011.

[9] Energy Environment Agency, Energy Environment Agency," $10 \quad 01$ 2010. [Online]. Available: http://www.eea.europa.eu/data-and-maps/indicators/ transport-final-energy-consumption-bymode/assessment. [Zugriff am 2102 2013].

[10] G. Frey, J. Horst and U. Leprich, „Auswirkungen von Elektroautos auf den Kraftwerkspark und die CO2-Emissionen in Deutschland,“ Bundesministerium für Verkehr, Bau und Stadtentwicklung, Bonn, 2009.

[11] J. Figueira, S. Greco and M. Ehrgott, Multiple Criteria Decision Analsysis: State of the Art Surveys, New York: Springer Verlag, 2005.
[12] T. Gottschalk, S. Toyoda und P. Watts, „The Sustainable Mobility Project,“ World Business Council for Sustainable Development, 2001.

[13] V. Hauff, „Unsere gemeinsame Zukunft: Der Brundtlandbericht der Weltkommission für Umwelt und Entwicklung,“Eggenkamp Verlag, Greven, 1987.

[14] Jinengo, „Projektgruppendokumentation SCRM 2011,“ 511 2011. [Online]. Available: http://wwwis.informatik.uni-oldenburg.de/ dibo/pg_fb10/ endberichte/2011/SCRM.pdf. [Zugriff am 201302 21].

[15] S. Neininger, Die Entstehung von Feinstaub und die Gefahren für Mensch und Umwelt, München: Grin, 2010.

[16] U. Lambrecht, H. Diaz-Bone und U. Höpfner, „Bus, Bahn und Pkw auf dem Umweltprüfstand," iFeu Heidelberg, Heidelberg, 2001.

[17] T. Reichmann, Controlling mit Kennzahlen und Management Tools - Die systemgestützte ControllingKonzeption, München: Franz Vahlen Verlag, 2006.

[18] R. Rickborn, VISUM 12 Grundlagen, Berlin: epubli, 2012.

[19] A. Ruhland, Entscheidungsunterstützung zur Auswahl von Verfahren der Trinkwasseraufbereitung an den Beispielen Arsentfernung und zentraler Enthärtung, Berlin: Technische Universität Berlin, 2004.

[20] M. Schwarz, M. Birke und E. Beerheide, „Die Bedeutung sozialer Innovationen für eine nachhaltige Entwicklung,“ in Soziale Innovationen - Auf dem Weg zu einem postindustriellen Innovationparadigma, Wiesbaden, VS-Verlag für Sozialwissenschaften, 2010, pp. 165-180.

[21] U. Simon, Multikriterielle Bewertung von wasserwirtschaftlichen Maßnahmen aus gewässerökologischer Sicht - Beispiel Berlin, Berlin: Tenea Verlag, 2003.

[22] Umweltbundesamt, „Aktueller Strommix in Deutschland,“ Umweltbundesamt, Dessau-Roßlau, 2008.

[23] Umweltbundesamt, „Stickstoff - Zu viel des Guten?,“ Umweltbundesamt, Dessau-Roßlau, 2011.

[24] Umweltbundesamt, „Kurzinformation zum Thema Umweltzonen in Deutschland,“ Umweltbundesamt, Berlin, 2008.

[25] Umweltbundesamt, „Auswirkungen des Vekehrs,“ 1805 2012. [Online]. Available: http://www.umweltbundesamt.at/umweltsituation/ver kehr/auswirkungen_verkehr/. [Zugriff am $18 \quad 05$ 2012].

[26] B. Wagner vom Berg, F. Köster und J. Marx Gómez, „Elektromobilität: Zukunft oder Gegenwart? Förderung der Elektromobilität durch innovative Infrastruktur- und Geschäftsmodelle, “ in MKWI 2010 Working Conference on Automotive Services , Kassel, Frauenhofer IWES, 2010, pp. 111-124.

[27] R. Wunderer und A. Jaritz, Unternehmerisches Personalcontrolling - Evaluation der Wertschöpfung 
in Personalmanagement, 2. erw. Aufl.,Neuwied: Luchterhand Verlag, 2002.
[28] T. W. Zängler, Mikroanalyse Des Mobilitätsverhaltens in Alltag und Freizeit, Berlin: Springer DE, 2000. 